\title{
In Situ TEM Study of Diffusion Kinetics in Al/Ni Nanomaterials
}

Christopher E. Shuck ${ }^{1}$, Joshua M. Pauls ${ }^{1}$, Sergei Rouvimov ${ }^{2}$, Alexander S. Mukasyan ${ }^{1}$ and Arda Genc ${ }^{3}$

1. Department of Chemical and Bio-molecular Engineering, University of Notre Dame, Notre Dame, IN, USA

2. Department of Electrical Engineering, University of Notre Dame, Notre Dame, IN, USA

3. Thermo Fisher Scientific, Hillsboro, OR, USA

The solid-state diffusion in inorganic materials is a broad scientific area that has a long history with many challenges. These challenges include measurement artifacts (e.g. inaccuracies through mechanical sectioning), long experimental time at high temperatures and high work load. The artifacts may lead to difficulty in accurately measuring diffusion, especially at lower temperatures or when measuring surface or grain boundary diffusion rates. Recent in-situ heating capabilities in Transmission Electron Microscopy (TEM) allow for the resolution of these challenges, making it possible to run high temperature (up to $1000^{\circ} \mathrm{C}$ ) experiments inside the TEM column. This opens new horizons in solid state physics research, allowing for diffusion analysis at the nano-scale level. The paper addresses the in-situ TEM study of diffusion kinetics of the Ni/Al system.

The studied Ni/Al nano-structures were either composite particles fabricated by High Energy Ball Milling or multi layered deposited structures. The combination of techniques includes EDS compositional analysis, Selected Area Electron Diffraction, High Resolution TEM, and STEM imaging, has been employed to study the structural and compositional transformations in the samples during annealing. Thermo Fisher Titan 80-300 TEM has been employed for materials characterization. TEM cross-sectional samples were prepared by Thermo Fisher Helios SEM/FIB dual beam tool. Nano-Ex-i/v S/TEM heating holders have been used for in-situ experiments on Talos F200X TEM at Thermo Fisher Scientific Nanoport.

The Ni/Al samples were annealed at different temperatures $\left(350{ }^{\circ} \mathrm{C}, 425{ }^{\circ} \mathrm{C}, 450{ }^{\circ} \mathrm{C}\right)$ for various times (from $0.5 \mathrm{~s}$ to $60 \mathrm{~s}$ ), then analyzed to characterize the diffusion process. The diffusion of $\mathrm{Ni}$ into $\mathrm{Al}$ has been observed even at $350{ }^{\circ} \mathrm{C}$ for $0.5 \mathrm{~s}$ (Fig.1), resulting in the formation of the $\mathrm{Al}_{3} \mathrm{Ni}$ intermetallic phase at the Al-Ni interfaces. The increase of $\mathrm{Ni}$ composition in $\mathrm{Al}$ at $\mathrm{Ni} / \mathrm{Al}$ interface can easily be detected on HAADF STEM images (compare Fig. 1a and b) due to Z-contrast (the higher Ni concentration, the higher intensity at the interface, see Fig. 1c). The formation of the $\mathrm{Al}_{3} \mathrm{Ni}$ crystal phase at the Al-Ni interfaces is further supported by electron diffraction (compare Fig. 2b and d). EDS mapping and spectrometry coupled with a heated TEM stage (Fig. 3) allow for observation of composition changes in the sample and the formation of new crystalline phases. The intensity of the colors indicates the concentration of each element. It can be seen that measurable diffusion occurs at all temperatures. Additionally, that a reaction begins at the inner, concave region where the $\mathrm{Ni}$ concentration is amplified.

Based on the TEM results, the diffusion kinetics in the Ni/Al system has been quantified (Fig. 4). Within $425-475{ }^{\circ} \mathrm{C}$, Ni diffuses into the $\mathrm{Al}$ at a rate of $D_{N i \rightarrow A l}=8.75 \times 10^{-6} \mathrm{e}^{-\left(\frac{264 \mathrm{KV}}{\mathrm{RT}}\right)} \frac{\mathrm{cm}^{2}}{\mathrm{~g}}$. It was shown that initial surface diffusion in the $\mathrm{Ni} / \mathrm{Al}$ system leads to the rapid formation of the $\mathrm{Al}_{3} \mathrm{Ni}$ phase immediately after heating. This phase extends up to $20 \mathrm{~nm}$ after only $0.5 \mathrm{~s}$ of heating at $350 \mathrm{~K}$. Due to this rapid phase transformation, it is probable that the reaction initiates, and subsequently propagates, owing to solely 
solid-state mechanisms. The diffusion coefficients measured in nano-structures in this work showed significantly higher temperature dependence than previous data [1,2]. The theoretical explanation of the TEM/STEM observation is in progress [3].

\section{References:}

[1] K. Hirano, M. Cohen, B.L. Averbach, Acta Metallurgica, 11 (1963), p. 463.

[2] Handbook of the Physiochemical Properties of the Elements (Ed. G. Samsonov), Springer, 1968, p. 942.

[3] The authors acknowledge the support of this study by NDIIF and Thermo Fisher Scientific.

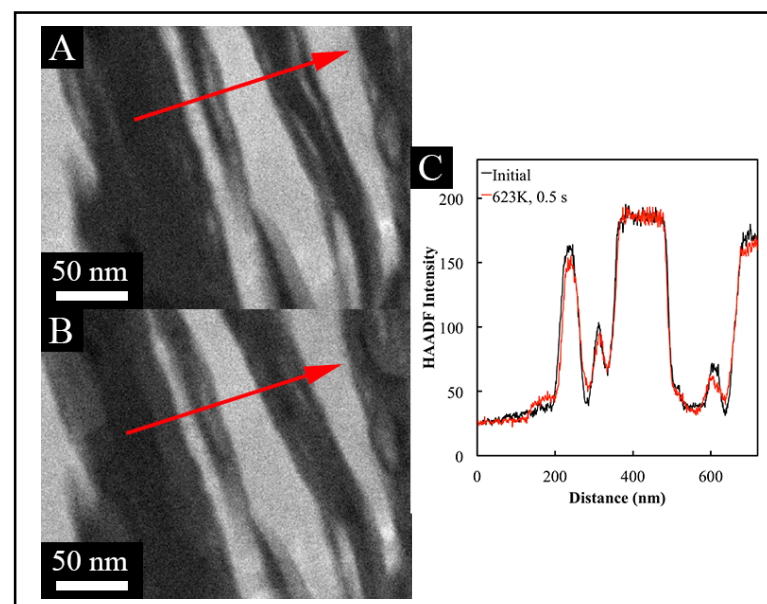

Figure 1. High-angle annular dark field (HAADF) scanning transmission electron microscopy (STEM) images are shown for the a) initial sample and b) sample heated at $623 \mathrm{~K}$ for $0.5 \mathrm{~s}$, along with the corresponding c) HAADF intensity plot.

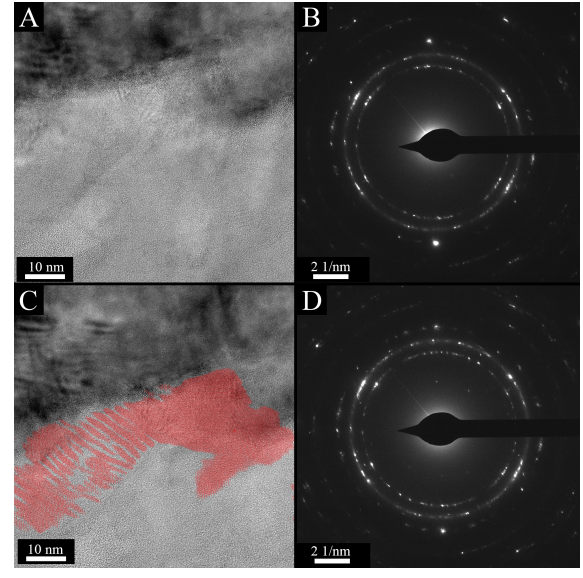

Figure 2. a) HRTEM images $(\mathrm{a}, \mathrm{c})$ and corresponding electron diffraction patterns $(b, d)$ of the area before $(a, b)$ and after $(c, d)$ annealing (350 C, 0.5s). The $\mathrm{Al}_{3} \mathrm{Ni}$ phase (associated with new diffraction spots in (d) is highlighted in red.

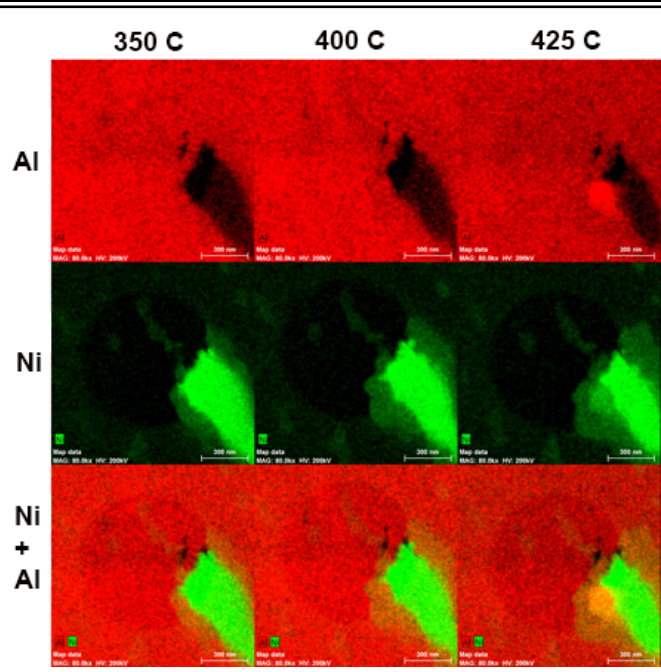

Figure 3. EDS maps of the $\mathrm{Ni}$ and $\mathrm{Al}$ phases after annealing at different temperatures.

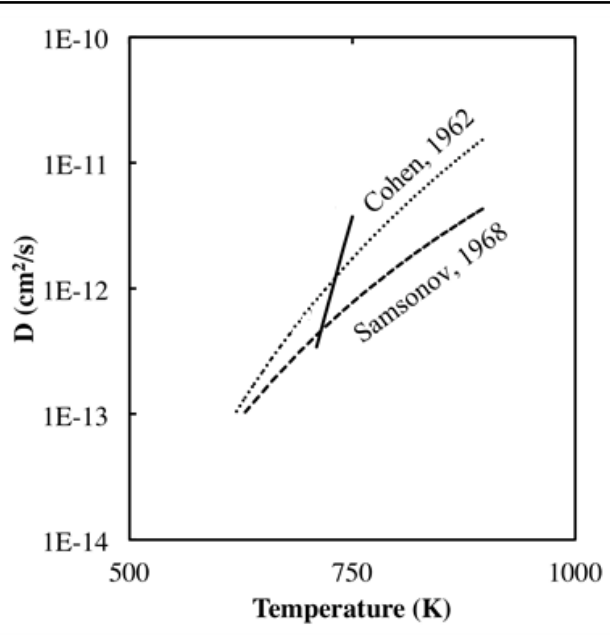

Figure 4. Comparison of the results obtained by different groups including the present work. 